\title{
A FIXED AXIS COILING MODEL FOR THE LIVING PLANKTONIC FORAMINIFER GLOBIGERINELLA SIPHONIFERA
}

BIJMA, Jelle, Inst. und Museum für Geologie und Paläontologie, Universität Tübingen, Sigwartstrasse 10, 7400 Tübingen, Germany; HUBER*, Brian T., Dept. of Paleobiology, MRC NHB-121, National Museum of Natural History, Smithsonian Institution, Washington, D.C. 20560 U.S.A.; HEMLEBEN, Christoph, Inst. und Museum für Geologie und Paläontologie, Universität Tübingen, Sigwartstrasse 10, 7400 Tübingen, Germany.

Two morphotypes of Globigerinella siphonifera (Types I and II) can be clearly distinguished in their natural environment based on differences in symbiont distribution, which is dependent on the structure of the pseudopodial network. Laboratory experiments have demonstrated that the life cycle and ecological requirements of Types I and II differ considerably as well. However, qualitative observation of the empty shells reveals no significant differences between these two morphotypes. Therefore, a "fixed-axis" coiling model has been developed to simulate foraminiferal shell morphology with a computer. The model is based on the assumption that isometry is the primary rule implemented in planktonic foraminiferal development. Four parameters (rate of radius increase, number of chambers per whorl, translation rate, and relative distance from the center of any chamber to the coiling axis) and two scaling factors (initial chamber size and number of chambers) suffice to generate geometric models of the shells of these planispirally coiled organisms.

Values for the four parameters extracted from digitized SEM microphotographs of dissected specimens of $G$. siphonifera demonstrate significant differences between the Types I and II. These are primarily due to a different rate of radius increase and a different number of chambers per whorl. Type I has a higher rate, which in combination with its lower number of chambers per whorl results in a more lobate test and a $22 \%$ smaller adult shell size than Type II. We suggest that the smaller surface area-to-volume ratio in the Type I population can be explained by increased respiration due to higher oxygen production during symbiotic photosynthesis; TEM has demonstrated that Type II contains twice as many symbionts than Type I and each symbiont contains a higher concentration of chloroplasts.

The fixed axis model was also used to describe the ontogeny of $G$. siphonifera. The model shows that early chambers in log-spirally coiled structures must deviate from a strict isometric arrangement. To maintain exponential growth, the juvenile stage of Types I and II is more planispiral, more umbilicated, and contains more chambers per whorl than the adult stage. Future investigations will focus on the transformation of the shape parameters during later ontogenetic development and during cladogenesis. 